Check for updates

Cite this: RSC Adv., 2017, 7, 52274

\title{
Control of the intrinsic microstructure in AP- PECVD synthesised amorphous silica thin films
}

\author{
F. M. Elam, iD *abc B. C. A. M. van der Velden-Schuermans, ${ }^{a}$ S. A. Starostin, ${ }^{a}$ \\ M. C. M. van de Sanden ${ }^{\text {bc }}$ and H. W. de Vries ${ }^{\star c}$
}

Amorphous single layered silica films deposited using industrially scalable roll-to-roll atmospheric pressure-plasma enhanced chemical vapor deposition were evaluated in terms of structureperformance relationships. Polarised attenuated total reflectance-Fourier transform infrared absorption spectroscopy and heavy water exposure to induce hydrogen-deuterium exchange revealed it was possible to control the film porosity simply by varying the precursor flux and plasma residence times. Denser silica network structures with fewer hydroxyl impurities, shorter $\mathrm{Si}-\mathrm{O}$ bonds, decreased $\mathrm{Si}-\mathrm{O}-\mathrm{Si}$ bond angles and a greater magnitude of isolated pores were found in films deposited with decreased precursor flux and increased plasma residence times, and consequently exhibited significantly improved encapsulation performance.

Received 5th October 2017

DOI: 10.1039/c7ra10975j

rsc.li/rsc-advances

rates, whilst maintaining a constant power dissipation in the discharge). ${ }^{\mathbf{1 0 , 1 2}}$ X-ray photoelectron spectroscopy (XPS) was used to successfully determine the elemental composition and hence approximate $\mathrm{O}: \mathrm{Si}$ ratio of the films. ${ }^{\mathbf{1 0 , 1 2}}$ Unfortunately in these instances, XPS was unable to provide a sufficiently detailed insight into the changes in the silica network structure as a function of deposition input energy, and hence the impact this had upon the encapsulation performance of the films.

Attenuated total reflectance-Fourier transform infrared (ATR-FTIR) absorption spectroscopy with an un-polarised light source was therefore used as an alternative, to study the intrinsic microstructure of these amorphous silica films, with focus on the extent of hydroxyl $(-\mathrm{OH})$ impurities. ${ }^{10,12,23-27}$ It was shown that an improved encapsulation performance was due in part to a decrease in concentration of network disrupting silanol ( $\mathrm{Si}-\mathrm{OH})$ groups, thus implying that the microstructure of the silica lattice increased in density at higher specific deposition energies per precursor molecule. ${ }^{10,12}$ However, no direct detailed analysis of the $\mathrm{Si}-\mathrm{O}-\mathrm{Si}$ bonding was carried out to verify this assumption. Fortunately, this type of bonding can be resolved by performing ATR-FTIR absorption spectroscopy using a polarised light source.

However, ATR-FTIR analysis alone does not provide a complete representation of the degree of porosity within the silica films. Ellipsometric porosimetry (EP) and electrical impedance spectroscopy (EIS) were two alternative techniques used extensively by Perrotta $e t$ al. to very effectively characterise the nano-porosity, the pore size range and the presence of macroscale defects in the structure of silica layers. ${ }^{28-31}$ Due to the nature of these techniques, however, the majority of the analysis was performed on samples deposited upon rigid silicon wafers, rather than flexible polymer substrates. A full

${ }^{a}$ FUJIFILM Manufacturing Europe B.V., P.O. Box 90156, 5000 LJ Tilburg, The Netherlands. E-mail:f.m.elam@differ.nl

${ }^{b}$ Eindhoven University of Technology, Applied Physics, P.O. Box 513, 5600 MB Eindhoven, The Netherlands

${ }^{c}$ DIFFER - Dutch Institute for Fundamental Energy Research, P.O. Box 6336, $5600 \mathrm{HH}$ Eindhoven, The Netherlands.E-mail: h.w.devries@differ.nl 
characterisation of the nano-pore content of silica layers was unfortunately found to be problematic using EP if a polyethylene terephthalate substrate was used. ${ }^{31}$

A method unhindered by the composition of the substrate material, and therefore an alternative to EP and EIS, is a technique involving proton exchange via exposure to heavy water $\left(\mathrm{D}_{2} \mathrm{O}\right)$ and subsequent detection of said transfer using ATRFTIR, highlighted relatively recently by Liu et $a l .{ }^{32}$ This method can provide information relating to the total pore surface area and the extent of closed porosity. It is therefore possible, by using this procedure, to obtain a more comprehensive interpretation of the bonding arrangements in amorphous silica films deposited on polymer substrates using APPECVD.

The ability to economically produce functional films with a specific porosity would be highly advantageous in the encapsulation barrier market. Therefore, understanding the influence roll-to-roll AP-PECVD processing has upon the intrinsic microstructure (namely the $\mathrm{Si}-\mathrm{O}-\mathrm{Si}$ bonding and degree of closed porosity), and resulting encapsulation performance of the synthesised amorphous silica layers is of paramount interest, and hence forms the basis of this work. Focus will be placed on the utilisation of two complementary analytical techniques known to be suitable for the structural analysis of films deposited upon polymeric substrate materials, namely polarised ATR-FTIR and hydrogen-deuterium exchange.

\section{Experimental section}

Single layer amorphous silica-like films were deposited onto thermally stabilised optical grade polyethylene 2,6 naphthalate (PEN) foil (Teonex Q65FA, Teijin DuPont Films) with a width and thickness of $180 \mathrm{~mm}$ and $100 \mu \mathrm{m}$ respectively, using a glowlike AP dielectric barrier discharge in an industrially scalable roll-to-roll set-up open to ambient air. A schematic representation of the AP-PECVD reactor is shown in Fig. 1 and all basic device and thin film deposition parameters can be found in a recent publication by Elam et al. ${ }^{12}$ The reactor itself is in an ISO class 3 cleanroom, in accordance with ISO 14644-1 standards.

The PEN foil was positioned over the lower drum electrode and the foil transport speed was varied from 133-33 $\mathrm{mm} \mathrm{min}^{-1}$ to enable the deposition of uniform $\sim 150 \mathrm{~nm}$ barrier layers. A $63 \mu \mathrm{m}$ thick sacrificial polymer, polyethylene terephthalate (PET) (ASTERATM Functional Foils, AGFA), was used as the dielectric material for the upper drum electrode, with foil transport speed maintained at $50 \mathrm{~mm} \mathrm{~min}^{-1}$ in all cases. The reactant gases for every deposition were oxygen (technical grade) and tetraethyl orthosilicate $\left(\mathrm{Si}\left(\mathrm{OC}_{2} \mathrm{H}_{5}\right)_{4}\right.$, TEOS $)(\geq 99.0 \%$, Sigma-Aldrich). The precursor gas, TEOS, was injected via a controlled evaporation mixer unit (CEM-Technology, Bronkhorst HIGH-TECH B.V.), where the liquid precursor was combined with $1 \mathrm{slm}$ argon (technical grade). The carrier gas in all cases was nitrogen (technical grade), with a flow of $20 \mathrm{slm}$. All four gases were mixed before being released into the plasma. In order to vary the specific input energy per TEOS molecule and therefore the layer densities for the $150 \mathrm{~nm}$ barrier layers, the

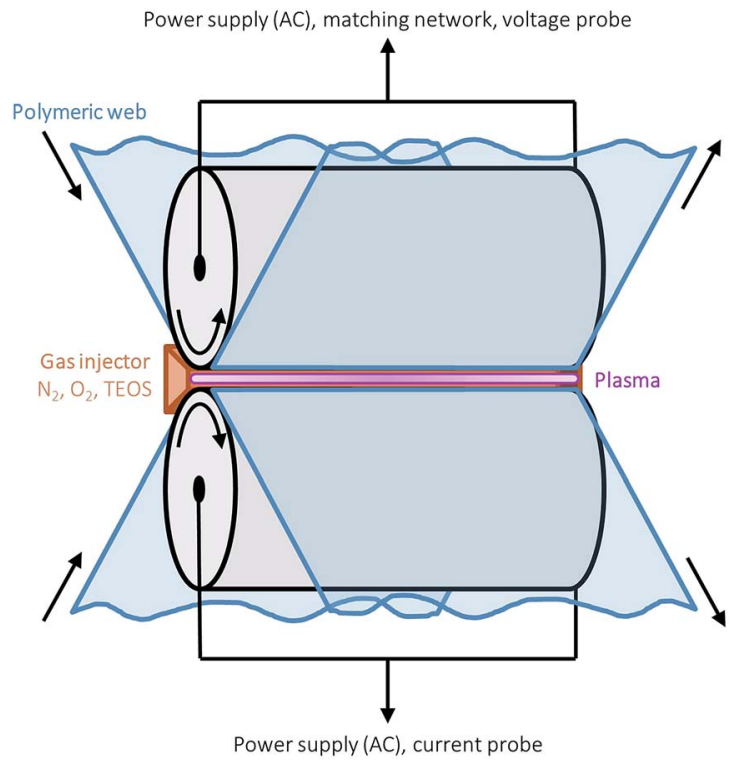

Fig. 1 Schematic of the roll-to-roll glow-like atmospheric pressure dielectric barrier discharge used for the deposition of all silica films by means of plasma enhanced chemical vapour deposition.

TEOS and oxygen gas flows were adjusted with a fixed ratio of $4.5 \times 10^{-3}$ in the range of $7.2 \times 10^{-3}$ to $1.8 \times 10^{-3}$ slm and 1.6$0.4 \mathrm{slm}$ respectively. This resulted in the deposition of barrier layers with input energies ranging from approximately 1.4-4.9 keV per TEOS molecule. A description of the method used to calculate the input energy per TEOS molecule (E per TEOS) is outlined in a publication by Elam et al. ${ }^{12}$

Spectroscopic ellipsometry (SE) was performed using a variable angle spectroscopic ellipsometer (M-2000D, J.A. Woollam Co. Inc.) in the wavelength range of $400-1000 \mathrm{~nm}$ in order to ensure that the single layer barriers post-deposition were of the expected thickness and demonstrated good overall uniformity. ${ }^{33}$ The Cauchy dispersion function was used to model the PEN substrate and the silica-like thin films as two separate entities. The optical model did not take into account the substrate anisotropy; ${ }^{\mathbf{1 4}}$ however sample orientation was consistent for each measurement.

The effective WVTR of the single layer samples comprising barrier and substrate layers were determined using a Deltaperm (Technolox Ltd.), with set conditions of $40{ }^{\circ} \mathrm{C}, 90 \%$ relative humidity (RH). This measurement therefore took into account the overall permeation of the films; including contributions from macro-defects $(>1 \mathrm{~nm})$, and the intrinsic microstructure (nano-defects (0.3-1 $\mathrm{nm}$ ) and gas transport through the amorphous silica-like lattice itself $(0.2-0.3 \mathrm{~nm})) .{ }^{17}$ The Deltaperm fulfils the ASTM D 1434-82 (2003) standard for permeation measurements, and has a WVTR limit of $2 \times 10^{-4} \mathrm{~g} \mathrm{~m}^{-2}$ day $^{-1}$. Sample areas of $50 \mathrm{~cm}^{2}$ were investigated, with each measurement lasting for 60-190 h depending on encapsulating ability, in order to ensure the permeation rate had stabilised. The WVTR was recorded each minute, and calculated as summarised in ref. 12. From the Deltaperm measurements, data concerning the lag-time (the time taken for the WVTR to reach 
a steady-state) was also obtained, and from this the apparent diffusion coefficient of the encapsulation layers calculated as outlined in ref. 12. It should be noted that all barrier layers used for the encapsulation performance measurements showed excellent adhesion to the polymeric substrate. No evidence of delamination was observed after evaluation using a cross-cut tape adhesion test (in accordance with ISO 2409:2003). ${ }^{\mathbf{1 0}}$

Attenuated total reflectance-Fourier transform infrared (ATR-FTIR) absorption spectroscopy was performed using spolarised light (Frontier FT-IR/FIR Spectrometer, PerkinElmer; VeeMAX III Accessory, PIKE Technologies) to investigate the average chemical structure of the barrier layers, ${ }^{34}$ with particular focus upon the Si-O-Si stretching modes. This set-up utilised a Ge crystal with a $60^{\circ}$ face angle and one internal reflection. Spectra were obtained at a set angle of $60^{\circ}$ (and hence a $60^{\circ}$ effective angle $\theta_{\mathrm{e}}$ ), which resulted in a penetration depth $d_{\mathrm{p}}$ range of 391-678 $\mathrm{nm}$ for the selected wavenumber range of $1300-750 \mathrm{~cm}^{-1}$, calculated using eqn (1), ${ }^{35}$

$$
d_{\mathrm{p}}=\frac{1}{100 \bar{\nu}\left(2 \pi\left(n_{1}^{2} \sin ^{2} \theta_{\mathrm{e}}-n_{2}^{2}\right)^{1 / 2}\right)}
$$

where $\bar{\nu}$ is the wavenumber, $n_{1}$ is the refractive index of the Ge crystal (4.0) and $n_{2}$ is the refractive index of the silica layer (1.48). To minimise the effect of background noise, 16 scans were acquired for every measurement. The absorption spectrum of the substrate was subtracted from each sample spectrum. In addition, every sample spectrum was normalised to the $\mathrm{Si}-\mathrm{O}-\mathrm{Si}$ asymmetric stretch peak centred at approximately $1050 \mathrm{~cm}^{-1}$, and interpreted assuming that an increase in peak absorption intensity equated to an increase in the presence of the corresponding functional group. Deconvolution of all spectral peaks was carried out (Peak Analyzer - Fit Peaks (Pro), OriginPro 9.1) in order to determine the position, full width at half maximum (FWHM) and intensity of each elementary contribution. For the purpose of this analysis, a separate set of samples were investigated as the PEN substrate has strong IR absorption peaks in the spectral region of interest for silica-like film evaluation. Therefore, a set of equivalent barrier layer-type films that had been deposited onto a PET substrate pre-coated with a $1 \mu \mathrm{m}$ thick layer of polyvinylidene chloride (PVDC) were analysed instead. The PVDC layer was thick enough to prevent penetration of the IR evanescent wave into the underlying PET substrate, and its FTIR absorption spectrum neutral enough not to impede the absorption spectrum of the silica layers, thereby ensuring 'clean' spectra of the films could be obtained. All equivalent barrier layer-type films were $\sim 200 \mathrm{~nm}$ in thickness, as it is known, especially when using polarised light, that both the FTIR absorption peak positions and FWHM can vary as a function of film thickness. ${ }^{36-40}$

The pore interconnectivity within the $150 \mathrm{~nm}$ silica-like barrier layers deposited on PEN, was determined by means of exposure to deuterium oxide $\left(\mathrm{D}_{2} \mathrm{O}\right)$ (Sigma-Aldrich) and subsequent detection of hydrogen-deuterium $\left({ }^{1} \mathrm{H}-{ }^{2} \mathrm{H}, \mathrm{H}-\mathrm{D}\right)$ exchange using un-polarised ATR-FTIR absorption spectroscopy (Frontier FT-IR/FIR Spectrometer, PerkinElmer; Frontier UATR Ge/Ge, PerkinElmer). This accessory similarly used a Ge crystal with one internal reflection, but a $45^{\circ}$ face angle. Spectra were acquired at a fixed angle of $45^{\circ}$, which resulted in a penetration depth range of 176-330 $\mathrm{nm}$ for the selected wavenumber range of $3750-2000 \mathrm{~cm}^{-1}$ (calculated as before using eqn (1)) and thus improved the detection and subsequent analysis of $\mathrm{SiO}-\mathrm{H}$ and $\mathrm{H}-\mathrm{OH}$ spectral peaks. The full procedure comprised drying the samples in a desiccator under vacuum for one week, followed by exposure to $\mathrm{D}_{2} \mathrm{O}$ for one week using a climate chamber, with set conditions of $40{ }^{\circ} \mathrm{C}, 90 \% \mathrm{RH}$. Samples were then dried again for one week in a desiccator under vacuum and finally exposed to ambient air for one week. ATR-FTIR absorption spectra were recorded directly after every step.

\section{Results and discussion}

\section{Encapsulation performance}

The effective WVTR trend (at $40{ }^{\circ} \mathrm{C}, 90 \% \mathrm{RH}$ ) with respect to increasing input energy per TEOS molecule (a parameter that relates increasing plasma residence time, or substrate transport speed, with decreasing TEOS vapour flow rates, whilst maintaining a constant power dissipation in the discharge) during
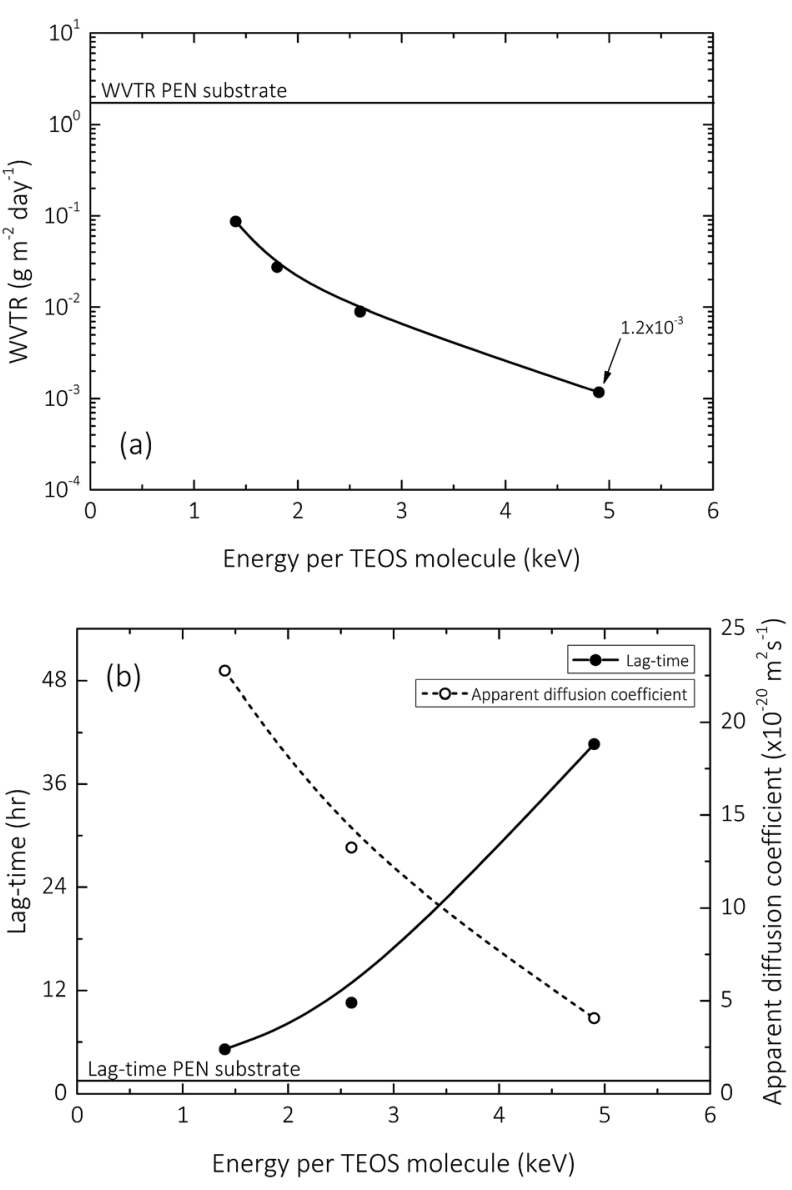

Fig. 2 Water permeation measurements (at $40{ }^{\circ} \mathrm{C}, 90 \%$ relative humidity): (a) water vapour transmission rate with respect to increasing input energy per TEOS molecule for synthesis of a $150 \mathrm{~nm}$ barrier layer; (b) lag-time and corresponding apparent diffusion coefficient with respect to increasing input energy per TEOS molecule for synthesis of a $150 \mathrm{~nm}$ barrier layer. 
the deposition of the $150 \mathrm{~nm}$ barrier layer is shown in Fig. 2a. As previously reported, a clear correlation can be observed between increasing input energy per TEOS molecule and decreasing effective WVTR, suggesting that the encapsulation properties of silica-like films deposited using AP-PECVD improve as a function of increased deposition input energy. ${ }^{\mathbf{1 0}}$ However, this improvement is unfortunately limited by the formation of macro-defects that occur as a result of the gradually intensified processing conditions required to achieve deposition input energies greater than $6 \mathrm{keV}$ per TEOS for single layered films and $20 \mathrm{keV}$ per TEOS for bilayer films. ${ }^{12,13}$ Fig. $2 \mathrm{~b}$ that illustrates the lag-time and apparent diffusion coefficient of the single layer barrier as a function of input energy per TEOS molecule, complements the WVTR data, reaffirming the above statements that encapsulation performance improves to a certain extent with increasing input energy per TEOS molecule during the deposition process.

\section{Silica network structure: polarised ATR-FTIR spectroscopy}

Fig. 3 and 4 show the normalised s-polarised ATR-FTIR absorption spectra and subsequent deconvolution, of the amorphous silica barrier layers deposited by AP-PECVD, with particular focus upon the Si-O-Si stretching modes. The presence of the silanol ( $\mathrm{Si}-\mathrm{OH}$ ) group in amorphous silica deposited using AP-PECVD is discussed in greater detail in a recent publication by Elam et al. ${ }^{12}$ For the purpose of understanding the extent and nature of the variation in film structure as a function of increasing input energy per TEOS molecule during the deposition process, the data set was extended to include samples deposited at energies up to $70 \mathrm{keV}$ per TEOS molecule. ${ }^{12}$

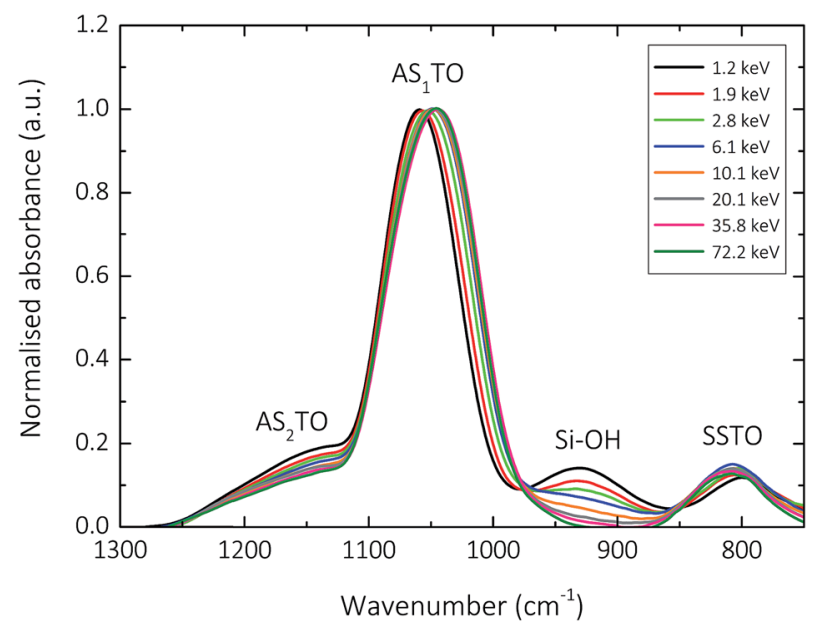

Fig. 3 Normalised s-polarized ATR-FTIR absorption spectra showing: the $\mathrm{Si}-\mathrm{O}-\mathrm{Si}$ transverse optical symmetric stretch (SSTO, $\sim 800 \mathrm{~cm}^{-1}$ ); the silanol stretch $\left(\mathrm{Si}-\mathrm{OH}, 930 \mathrm{~cm}^{-1}\right)$; the $\mathrm{Si}-\mathrm{O}-\mathrm{Si}$ transverse optical asymmetric stretch with adjacent $O$ atoms in phase $\left(\mathrm{AS}_{1} \mathrm{TO}\right.$, $\left.\sim 1050 \mathrm{~cm}^{-1}\right)$; and the $\mathrm{Si}-\mathrm{O}-\mathrm{Si}$ transverse optical asymmetric stretch with adjacent $O$ atoms $180^{\circ}$ out of phase $\left(\mathrm{AS}_{2} \mathrm{TO}, \sim 1160 \mathrm{~cm}^{-1}\right)$ of $200 \mathrm{~nm}$ silica-like thin films deposited with input $E$ per TEOS from 1.2$72.2 \mathrm{keV}$ onto a modified PET substrate using AP-PECVD, under conditions replicating those of the barrier layer synthesis.
Amorphous silica, unlike conventional crystalline silicon dioxide $\left(\mathrm{SiO}_{2}\right)$, does not possess a silicon-oxygen ( $\left.\mathrm{Si}-\mathrm{O}\right)$ microstructure with obvious long range order. ${ }^{39,41}$ The crystal symmetry is broken by disordered linkage, and by the existence of oxygen atoms that are not shared among neighbouring tetrahedra. This disorder therefore gives rise to localisation, and hence the vibrational properties of amorphous silica are usually interpreted in terms of $\mathrm{Si}-\mathrm{O}-\mathrm{Si}$ subunits. ${ }^{41}$ However, due to its lattice-like network structure, longitudinal optical (LO) and transverse optical (TO) phonons associated with the Si-OSi symmetric (SS) and asymmetric stretching (AS) modes also exist. ${ }^{\mathbf{4 2 - 4 4}}$ It is possible to activate the LO modes with a transition dipole moment oriented perpendicular to the surface of the film, ${ }^{45,46}$ by utilising the p-polarised component of IR light in oblique-incidence reflectance. ${ }^{46-48}$

In a similar fashion, TO modes oriented parallel to the surface, ${ }^{45,46}$ are activated alongside LO modes, but can be isolated by using s-polarised light. ${ }^{48}$ Furthermore, the $\mathrm{Si}-\mathrm{O}-\mathrm{Si}$ asymmetric stretching mode in fact generates two vibrational modes: the $\mathrm{AS}_{1}$ mode whereby adjacent oxygen atoms execute the asymmetric stretching motion in phase with one another, and the $\mathrm{AS}_{2}$ mode characteristic of the $\mathrm{Si}-\mathrm{O}-\mathrm{Si}$ shoulder peak, in which adjacent oxygen atoms perform the asymmetric stretch $180^{\circ}$ out of phase. ${ }^{49-51}$ This therefore results in six IR active modes associated with the $\mathrm{Si}-\mathrm{O}-\mathrm{Si}$ functional group; namely the TO and LO phonons for the symmetric stretch (SSTO and SSLO), and the TO and LO phonons for both asymmetric stretches $\left(\mathrm{AS}_{1} \mathrm{TO}, \mathrm{AS}_{2} \mathrm{TO}, \mathrm{AS}_{1} \mathrm{LO}\right.$ and $\left.\mathrm{AS}_{2} \mathrm{LO}\right) .^{51}$

The most prominent peaks in the normalised s-polarised ATR-FTIR absorption spectrum of amorphous silica shown in Fig. 3 can be assigned to the Si-O-Si SSTO mode $\left(\sim 800 \mathrm{~cm}^{-1}\right)$, the silanol $(\mathrm{Si}-\mathrm{OH})$ stretch $\left(930 \mathrm{~cm}^{-1}\right)$, the $\mathrm{Si}-\mathrm{O}-\mathrm{Si} \mathrm{AS} \mathrm{AO}_{1}$ mode $\left(\sim 1050 \mathrm{~cm}^{-1}\right)$ and the Si-O-Si AS $\mathrm{AO}_{2}$ mode $\left(\sim 1160 \mathrm{~cm}^{-1}\right)$. It should be highlighted that no peaks at $1275 \mathrm{~cm}^{-1}$ due to the bending mode of methyl groups in $\mathrm{Si}-\mathrm{CH}_{3}$ are observed, ${ }^{24,52-54}$ indicating that all silica-like films deposited using the APPECVD process are essentially carbon free. This assumption has also been verified by prior XPS analysis, which revealed the maximum percentage of elemental carbon present in the silica layers was $3.5 \% .^{10,12}$

Several clear trends become apparent upon deconvolution (Fig. 4) of the spectra shown in Fig. 3. The absorbance of the SSTO mode increases with increasing input energy per TEOS molecule during the deposition process. According to the BeerLambert law, ${ }^{12}$ this implies an increase in concentration of SiO-Si species and thus reduction in the porosity of the intrinsic microstructure of the silica network as a function of increasing deposition input energy. Contrary to this, however, the absorbance of the $\mathrm{AS}_{2} \mathrm{TO}$ vibrational mode decreases. An increase in the intensity of the $\mathrm{AS}_{2} \mathrm{TO}$ mode has been previously associated with disorder-induced mechanical coupling to the $\mathrm{AS}_{1}$ mode, ${ }^{50,51,55}$ increased porosity in the layer, ${ }^{56}$ and increased disorder in the silica microstructure. ${ }^{25,27,50,55}$ Therefore a decrease in the intensity of the $\mathrm{AS}_{2} \mathrm{TO}$ vibrational mode would also indicate a reduction in porosity and hence densification of the intrinsic microstructure of the silica network. 

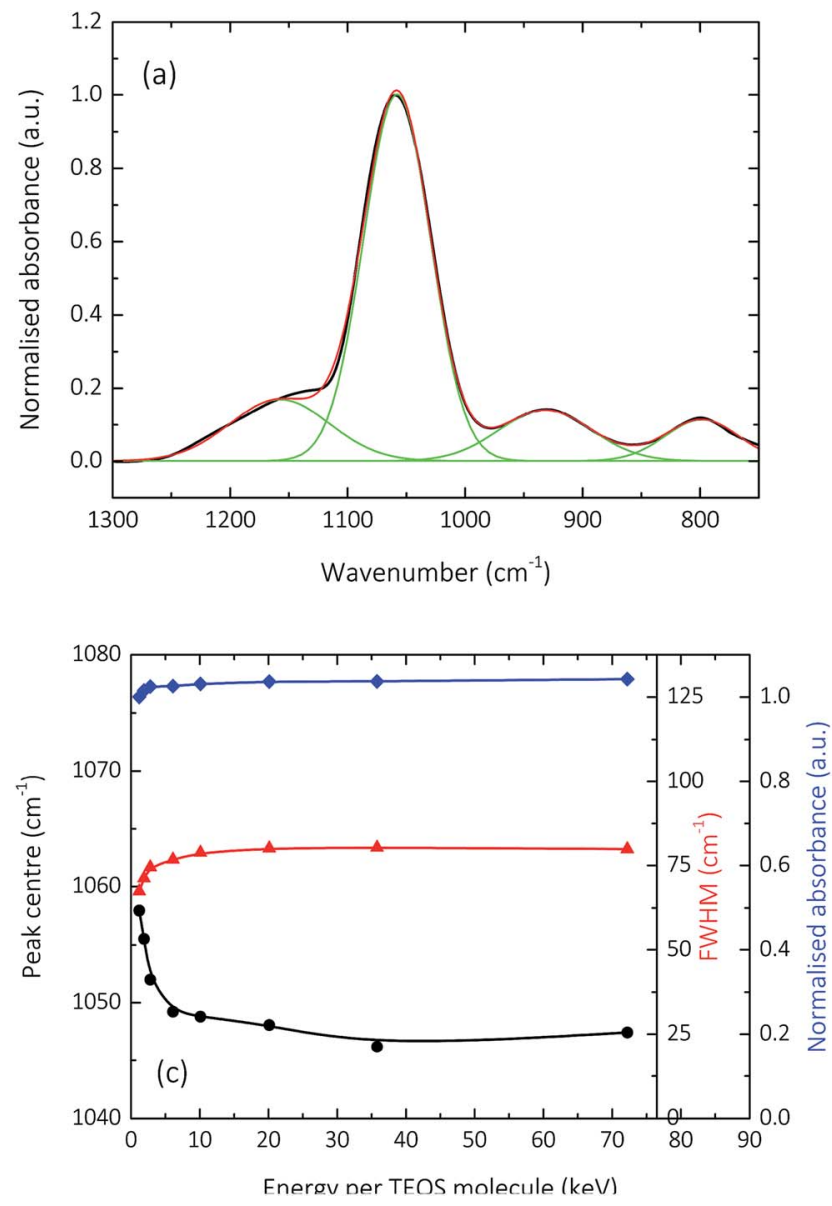
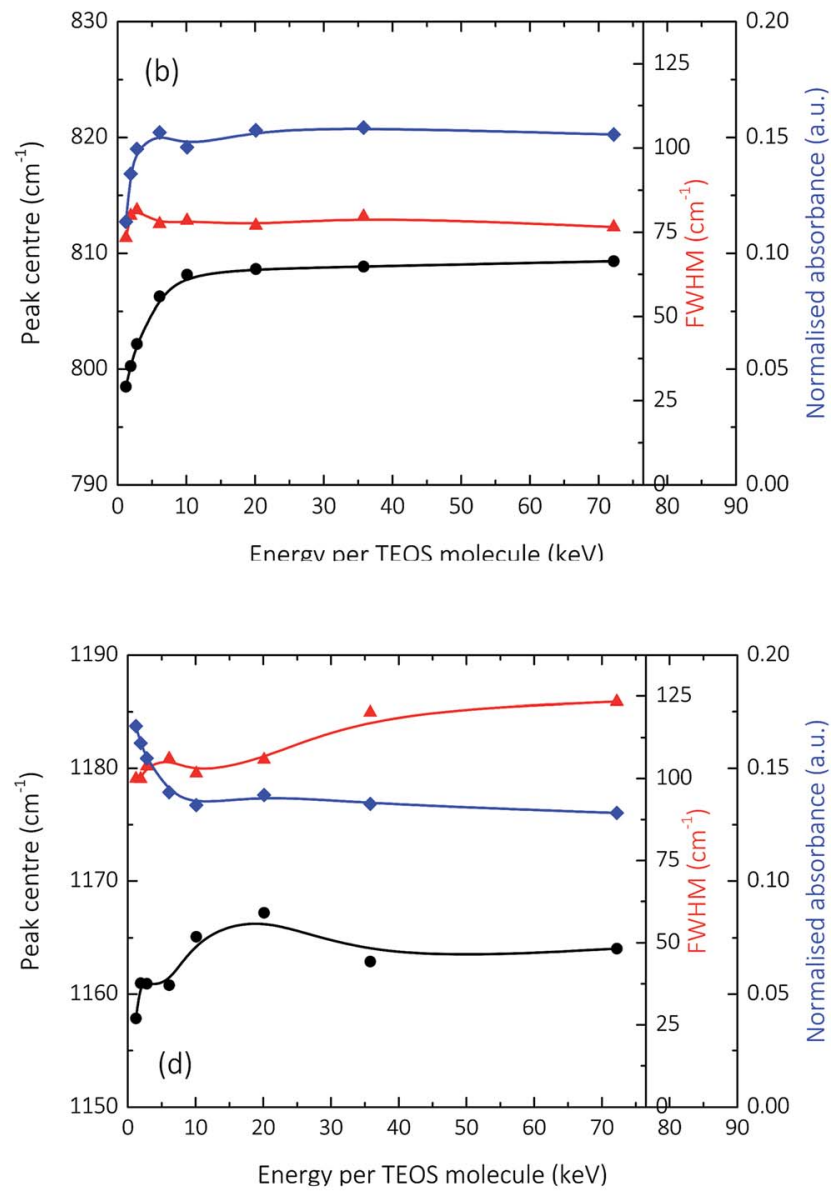

Fig. 4 Deconvolution (a) of the normalised s-polarized ATR-FTIR absorption spectra shown in Fig. 3 illustrating the specific peak centre (black; circle), FWHM (red; triangle) and absorbance (blue; diamond) as a function of increasing input E per TEOS for the synthesis of the barrier layer for: (b) Si-O-Si SSTO; (c) Si-O-Si AS ${ }_{1} \mathrm{TO}$ and (d) $\mathrm{Si}-\mathrm{O}-\mathrm{Si} \mathrm{AS}_{2} \mathrm{TO}$.

The peak FWHM, widely acknowledged to be indicative of the degree of variation in bonding arrangements surrounding a particular functional group, ${ }^{50,57-59}$ can be seen to increase for all Si-O-Si stretching modes, as the deposition input energy increases. As the intrinsic silica network densifies with a reduction in the concentration of network-disrupting silanol groups ${ }^{12}$ the distribution of $\mathrm{Si}-\mathrm{O}-\mathrm{Si}$ bond angles in the network is likely to increase, thereby resulting in an increase in the FWHM..$^{23,60}$ The greater distribution of bond angles may also coincide with an increase in bond strain and thus film tensile stress. ${ }^{61}$

The specific peak centres of the SSTO and $\mathrm{AS}_{2} \mathrm{TO}$ vibrations are observed to increase in wavenumber with increasing film density, ${ }^{62}$ most likely the consequence of an increase in the force constant $k$, of the $\mathrm{Si}-\mathrm{O}-\mathrm{Si}$ bonds since the reduced mass of the vibrating atoms $\mu$, remains unchanged. ${ }^{63}$ Due to the removal of network-disrupting $\mathrm{Si}-\mathrm{OH}$ groups,${ }^{12}$ the length of $\mathrm{Si}-\mathrm{O}$ bonds are liable to decrease, resulting in an increase in bond strength and thus rise in vibrational frequency as a function of increasing deposition input energy. Conversely, the specific peak centre of the $\mathrm{AS}_{1} \mathrm{TO}$ vibrational mode is quite visibly seen to decrease in wavenumber as a function of increasing input energy per TEOS molecule and hence reduction in porosity. This effect was also previously observed in conjunction with removal of hydroxyl species, ${ }^{23,60}$ and densification. ${ }^{62}$ Slight variations in peak positions can also be attributed to changes in the intrinsic bond angles, as described in eqn (2), which is specific for the $\mathrm{Si}-$ O-Si vibration:

$$
\omega^{2}=\frac{k}{m_{\mathrm{O}}}(1-\cos \theta)+\frac{4}{3} \frac{k}{m_{\mathrm{Si}}}
$$

where $\omega$ is the stretching frequency, $m_{\mathrm{O}}$ and $m_{\mathrm{Si}}$ are the mass of oxygen and silicon atoms respectively, $\theta$ is the $\mathrm{Si}-\mathrm{O}-\mathrm{Si}$ intertetrahedral bond angle and $k$ in this case is the $\mathrm{Si}-\mathrm{O}$ stretching force constant. ${ }^{27}$ And so, any decrease in frequency of the $\mathrm{Si}-$ $\mathrm{O}-\mathrm{Si} \mathrm{AS}_{1}$ vibration can theoretically be associated with a decrease in the $\mathrm{Si}-\mathrm{O}-\mathrm{Si}$ bond angle, within the range $90-180^{\circ}$, and consequently, like the aforementioned increase in FWHM, also an indication of an increase in strain within the $\mathrm{Si}-\mathrm{O}-\mathrm{Si}$ structure. ${ }^{57-59}$

Therefore the presented ATR-FTIR analysis suggests that the intrinsic micro-structure of AP-PECVD synthesised amorphous silica densifies as a function of increasing deposition input energy. The densification is confirmed by an increase in the presence of Si-O-Si groups due to removal of hydroxyl species, ${ }^{12}$ 

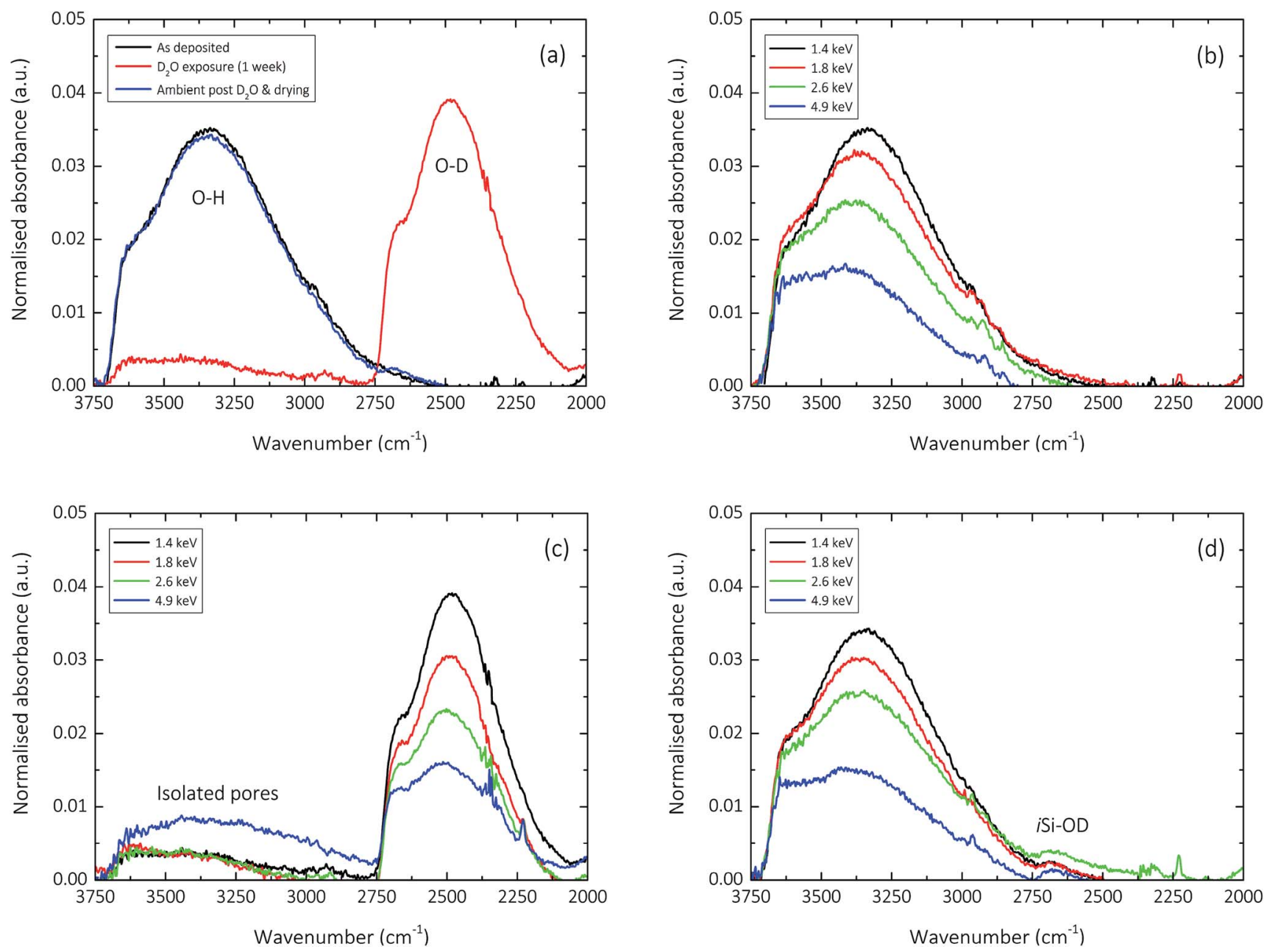

Fig. 5 Normalised un-polarized ATR-FTIR absorption spectra showing: (a) the influence of the $\mathrm{D}_{2} \mathrm{O}$ exposure process upon the hydroxyl (O-H, $3750-3000 \mathrm{~cm}^{-1}$; O-D, 2750-2250 $\mathrm{cm}^{-1}$ ) stretching region for a $150 \mathrm{~nm}$ silica-like thin film deposited with an input E per TEOS of $1.4 \mathrm{keV}$; the hydroxyl stretching region of $150 \mathrm{~nm}$ silica-like thin films deposited with input E per TEOS ranging from 1.4-4.9 keV illustrating films (b) immediately after deposition; (c) after one week exposure to $\mathrm{D}_{2} \mathrm{O}$ and (d) after one week exposure to ambient air (post $\mathrm{D}_{2} \mathrm{O}$ contact).

a decrease in $\mathrm{Si}-\mathrm{O}$ bond lengths and decrease in $\mathrm{Si}-\mathrm{O}-\mathrm{Si}$ bond angle which may in turn result in increased bond strain. The findings suitably confirm the improved encapsulation performance observed as a function of increasing deposition input energy shown in Fig. 2.

However, as illustrated in Fig. 4b-d, the silica network regarding the $\mathrm{Si}-\mathrm{O}-\mathrm{Si}$ bonding appears to rapidly densify and then plateau at deposition input energies of approximately $6-10 \mathrm{keV}$ per TEOS. This does not entirely coincide with the prior reported ATR-FTIR analysis focussed on the hydroxyl content of the films, ${ }^{12}$ which showed a more gradual removal of silanol impurities as a function of deposition input energy up to at least $\sim 35 \mathrm{keV}$ per TEOS. This finding would imply that a potential two-part densification process occurs as a function of increasing deposition input energy for amorphous silica films synthesised using AP-PECVD. First, rapid densification of the silica network takes place, alongside the steady removal of hydroxyl impurities for films synthesised at specific deposition E per TEOS up to $\sim 6 \mathrm{keV}$. The silica network then continues to densify, but at a much slower rate, in line with the gradual to almost complete removal of hydroxyl impurities only seen for films deposited at specific energies greater than $\sim 35 \mathrm{keV}$ per TEOS. ${ }^{12}$

\section{Pore interconnectivity: hydrogen-deuterium exchange}

The influence of the $\mathrm{D}_{2} \mathrm{O}$ exposure process performed to understand pore interconnectivity in the $150 \mathrm{~nm}$ silica-like thin films can be seen in the normalised un-polarised ATR-FTIR absorption spectra shown in Fig. 5. Hydrogen-deuterium exchange, due to the increase in reduced mass of the vibrating atoms $\mu$, induces a detectable decrease in the frequency of the $\mathrm{O}-\mathrm{H}$ vibration. ${ }^{63}$ This is clearly evident for all films upon exposure to $\mathrm{D}_{2} \mathrm{O}$, and is seemingly reversible upon subsequent drying and contact with ambient air.

As previously discussed by Elam et al., ${ }^{12}$ the hydroxyl groups in the amorphous silica network, whether covalently bonded as in the case of isolated silanol (iSiO- $\mathrm{H}, 3650 \mathrm{~cm}^{-1}$ ), $, 33,54,60$ and neighbouring silanol (nSiO-H, $\left.3450 \mathrm{~cm}^{-1}\right),{ }^{53,54,64}$ or unbound in the case of trapped molecular water $\left(\mathrm{HO}-\mathrm{H}, 3250 \mathrm{~cm}^{-1}\right), 27,54,64$ 


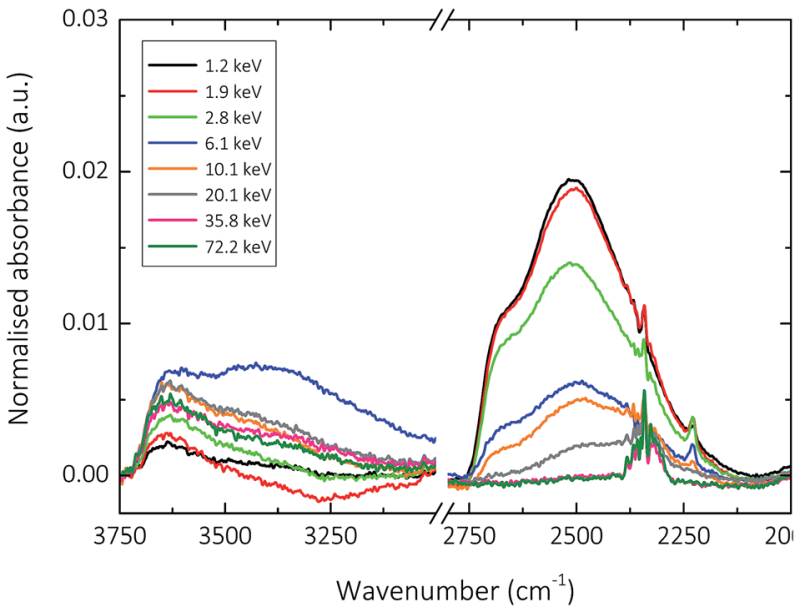

Fig. 6 Normalised un-polarized ATR-FTIR absorption spectra showing the influence of one week exposure to $\mathrm{D}_{2} \mathrm{O}$ upon the hydroxyl $\left(\mathrm{O}-\mathrm{H}, 3750-3000 \mathrm{~cm}^{-1}\right.$; O-D, 2750-2250 $\left.\mathrm{cm}^{-1}\right)$ stretching region for $200 \mathrm{~nm}$ silica-like thin films deposited with input E per TEOS ranging from 1.2-72.2 keV onto a modified PET substrate using APPECVD, under conditions replicating those of the barrier layer synthesis. The peaks at $\sim 2350 \mathrm{~cm}^{-1}$ are due to the carbon dioxide asymmetric stretch.

gradually decrease in concentration with increasing deposition input energy. This characteristic decrease in absorbance can be seen clearly in Fig. 5b. However, what becomes apparent upon exposure to $\mathrm{D}_{2} \mathrm{O}$, is the variation in the degree of pore interconnectivity. It appears that samples deposited at specific energies greater than $2.6 \mathrm{keV}$ per TEOS molecule have a greater magnitude of isolated pores within the silica network (Fig. 5c), as the extent of $\mathrm{H}-\mathrm{D}$ exchange during the one week exposure is significantly less for samples deposited at $4.9 \mathrm{keV}$ per TEOS molecule. This finding directly correlates with the one order of magnitude improvement in encapsulation performance $\left(10^{-2}\right.$ to $10^{-3} \mathrm{~g} \mathrm{~m}^{-2}$ day $^{-1}$ ) observed for films deposited at $4.9 \mathrm{keV}$ per TEOS with respect to $2.6 \mathrm{keV}$ per TEOS (Fig. 2). Upon drying of the samples post $\mathrm{D}_{2} \mathrm{O}$ exposure and subsequent contact with ambient air for one week, it appears in general that the reverse deuterium-hydrogen exchange occurs, bar a small concentration of deuterium that still remains in all films, covalently bonded in the form of isolated silanol (iSiO-D), as shown in Fig. 5 d.

For the purpose of understanding pore interconnectivity in amorphous silica thin films deposited at energies greater than $4.9 \mathrm{keV}$, the data set was extended to include samples deposited at energies up to $70 \mathrm{keV}$ per TEOS molecule. The results showing the influence of one week exposure to $\mathrm{D}_{2} \mathrm{O}$ on the hydroxyl stretching region of these films can be seen in Fig. 6 .

From the aforementioned polarised ATR-FTIR analysis of these films, it was proposed that a two-part densification process occurs as a function of increasing specific energy during the deposition of amorphous silica films using AP-PECVD. The silica network structure was thought to initially undergo a rapid densification for films synthesised at specific deposition E per TEOS up to $\sim 6 \mathrm{keV}$, alongside the steady removal of hydroxyl impurities. This phenomenon can be seen in Fig. 6, with films deposited at energies lower and higher than $\sim 6 \mathrm{keV}$ displaying different behaviour regarding $\mathrm{H}-\mathrm{D}$ substitution. Films deposited at specific energies $<6 \mathrm{keV}$ show almost complete $\mathrm{H}-\mathrm{D}$ substitution, suggesting that the silica network is open enough to permit the unhindered permeation of (heavy)water molecules and thus the exchange of hydrogen and deuterium, even for supposedly isolated silanol groups. For films deposited at a specific deposition energy of $\sim 6 \mathrm{keV}$ however, the pore interconnectivity decreases (the $\mathrm{Si}-\mathrm{O}$ bond length and $\mathrm{Si}-\mathrm{O}-\mathrm{Si}$ bond angle decreases) to such a degree that only hindered permeation of (heavy)water molecules is permitted, leading merely to partial H-D substitution. This observation holds true for films deposited at energies up to $\sim 20 \mathrm{keV}$, after which no $\mathrm{H}-\mathrm{D}$ substitution is observed. Amorphous silica films deposited at specific energies $>20 \mathrm{keV}$ appear to have a network structure impermeable to (heavy)water molecules. The diameter of the pores within the lattice must therefore be $<0.265 \mathrm{~nm}$ (the kinetic diameter of water), making the few remaining hydroxyl impurities within the silica network of these films completely isolated.

This finding would imply that amorphous silica thin films deposited using AP-PECVD at specific energies greater than 20 $\mathrm{keV}$ should show excellent encapsulating ability due to their intrinsically dense nature. However, as mentioned before, the performance of these films can unfortunately be limited by the formation of macro-defects that occur as a result of the gradually intensified processing conditions necessary to achieve such high deposition input energies. ${ }^{12,13}$

\section{Conclusions}

The structure-performance relationships in single layer amorphous silica encapsulation films deposited using industrially scalable and cost-effective roll-to-roll AP-PECVD were evaluated. Extensive polarised ATR-FTIR analysis revealed the intrinsic micro-structure of the amorphous silica rapidly densified as a function of increasing deposition input energy, a parameter that related increasing plasma residence time with decreasing TEOS vapour flow rates. The network densification was confirmed by an increase in the presence of $\mathrm{Si}-\mathrm{O}-\mathrm{Si}$ groups, removal of hydroxyl species, a decrease in $\mathrm{Si}-\mathrm{O}$ bond length and decrease in $\mathrm{Si}-\mathrm{O}-\mathrm{Si}$ bond angle. In conjunction, exposure of the silica layers to $\mathrm{D}_{2} \mathrm{O}$ to induce hydrogen-deuterium exchange uncovered a transition in pore interconnectivity as a function of input deposition energy, with a greater magnitude of isolated pores incorporated into silica networks deposited at higher input energies. The technique also permitted the estimation of pore diameters within the lattice structures of the films found to be impermeable to (heavy)water molecules.

In addition, the findings exposed a clear correlation between encapsulation performance (WVTR and lag-time) and the intrinsic amorphous microstructure, proving that the intrinsic porosity of AP-PECVD silica films could be controlled merely by varying the deposition precursor flux and plasma residence times. The results presented in this article hereby demonstrate the remarkable potential of AP-PECVD as an economical, 
reliable and versatile production method for the synthesis of encapsulation films.

\section{Conflicts of interest}

There are no conflicts to declare.

\section{Acknowledgements}

This research received funding from the European Union's Seventh Framework Programme for research, technological development and demonstration under grant agreement number 606889; project ESR7 in the framework of the RAPID (Reactive Atmospheric Plasma processIng - eDucation network) Marie Curie Initial Training Network (http://www.rapid-itn.eu). The work is also in association with the Industrial Partnership Programme i31 (APPFF) that is carried out under an agreement between FUJIFILM Manufacturing Europe B.V. and FOM, which is part of the Netherlands Organisation for Scientific Research (NWO). The author would like to thank Rinie van Beijnen, Emile Gommers, Bruno Korngold and Yieuw-Wing Mok (FUJIFILM Manufacturing Europe B.V., Tilburg, The Netherlands) for their technical assistance.

\section{References}

1 J. Lewis, Mater. Today, 2006, 9, 38-45.

2 J.-S. Park, H. Chae, H. K. Chung and S. I. Lee, Semicond. Sci. Technol., 2011, 26, 34001.

3 N. Grossiord, J. M. Kroon, R. Andriessen and P. W. M. Blom, Org. Electron., 2012, 13, 432-456.

4 Y. C. Han, E. Kim, W. Kim, H.-G. Im, B.-S. Bae and K. C. Choi, Org. Electron., 2013, 14, 1435-1440.

5 P. E. Burrows, G. L. Graff, M. E. Gross, P. M. Martin, M. Hall, E. Mast, C. Bonham, W. Bennett, L. Michalski, M. Weaver, J. J. Brown, D. Fogarty and L. S. Sapochak, Proc. SPIE, 2001, 4105, 75-83.

6 M. S. Weaver, L. A. Michalski, K. Rajan, M. A. Rothman, J. A. Silvernail, J. J. Brown, P. E. Burrows, G. L. Graff, M. E. Gross, P. M. Martin, M. Hall, E. Mast, C. Bonham, W. Bennett and M. Zumhoff, Appl. Phys. Lett., 2002, 81, 2929-2931.

7 G. L. Graff, R. E. Williford and P. E. Burrows, J. Appl. Phys., 2004, 96, 1840-1849.

8 S.-W. Seo, E. Jung, C. Lim, H. Chae and S. M. Cho, Thin Solid Films, 2012, 520, 6690-6694.

9 A. Morlier, S. Cros, J. P. Garandet and N. Alberola, Sol. Energy Mater. Sol. Cells, 2013, 115, 93-99.

10 S. A. Starostin, M. Creatore, J. B. Bouwstra, M. C. M. van de Sanden and H. W. de Vries, Plasma Processes Polym., 2015, 12, 545-554.

11 P. A. Premkumar, S. A. Starostin, M. Creatore, H. de Vries, R. M. J. Paffen, P. M. Koenraad and M. C. M. van de Sanden, Plasma Processes Polym., 2010, 7, 635-639.

12 F. M. Elam, S. A. Starostin, A. S. Meshkova, B. C. A. M. van der Velden-Schuermans, J. B. Bouwstra, M. C. M. van de
Sanden and H. W. de Vries, Plasma Processes Polym., 2017, 14, 1600143.

13 F. M. Elam, S. A. Starostin, A. S. Meshkova, B. C. A. M. van der Velden-Schuermans, M. C. M. van de Sanden and H. W. de Vries, J. Phys. D: Appl. Phys., 2017, 50, 25 LT01.

14 G. Aresta, P. A. Premkumar, S. A. Starostin, H. de Vries, M. C. M. van de Sanden and M. Creatore, Plasma Processes Polym., 2010, 7, 766-774.

15 A. S. da Silva Sobrinho, G. Czeremuszkin, M. Latrèche and M. R. Wertheimer, J. Vac. Sci. Technol., A, 2000, 18, 149-157. 16 Y. Leterrier, Prog. Mater. Sci., 2003, 48, 1-55.

17 A. P. Roberts, B. M. Henry, A. P. Sutton, C. R. M. Grovenor, G. A. D. Briggs, T. Miyamoto, M. Kano, Y. Tsukahara and M. Yanaka, J. Membr. Sci., 2002, 208, 75-88.

18 S. Nagai, J. Appl. Phys., 2013, 114, 174302.

19 P. A. Premkumar, S. A. Starostin, H. de Vries, M. Creatore, P. M. Koenraad, W. A. MacDonald and M. C. M. van de Sanden, Plasma Processes Polym., 2012, 9, 1194-1207.

20 A. Perrotta, G. Aresta, E. R. J. van Beekum, J. Palmans, P. van de Weijer, M. C. M. van de Sanden, W. M. M. Kessels and M. Creatore, Thin Solid Films, 2015, 595, 251-257.

21 A. M. Coclite and K. K. Gleason, J. Appl. Phys., 2012, 111, 73516.

22 J. Petersen, J. Bardon, A. Dinia, D. Ruch and N. Gherardi, ACS Appl. Mater. Interfaces, 2012, 4, 5872-5882.

23 W. A. Pliskin, J. Vac. Sci. Technol., 1977, 14, 1064-1081.

24 J. Schafer, R. Foest, A. Quade, A. Ohl and K.-D. Weltmann, Plasma Processes Polym., 2009, 6, S519-S524.

25 A. Brunet-Bruneau, J. Rivory, B. Rafin, J. Y. Robic and P. Chaton, J. Appl. Phys., 1997, 82, 1330-1335.

26 S. C. Deshmukh and E. S. Aydil, Appl. Phys. Lett., 1994, 65, 3185-3187.

27 P. Innocenzi, J. Non-Cryst. Solids, 2003, 316, 309-319.

28 A. Perrotta, E. R. J. Van Beekum, G. Aresta, A. Jagia, W. Keuning, M. C. M. Van De Sanden, W. M. M. Kessels and M. Creatore, Microporous Mesoporous Mater., 2014, 188, 163-171.

29 A. Perrotta, S. J. García, J. J. Michels, A.-M. Andringa and M. Creatore, ACS Appl. Mater. Interfaces, 2015, 7, 1596815977.

30 A. Perrotta, S. J. García and M. Creatore, Plasma Processes Polym., 2015, 12, 968-979.

31 A. Perrotta, W. M. M. Kessels and M. Creatore, ACS Appl. Mater. Interfaces, 2016, 8, 25005-25009.

32 C.-N. Liu, B. Ozkaya, S. Steves, P. Awakowicz and G. Grundmeier, J. Phys. D: Appl. Phys., 2013, 46, 84015.

33 S. A. Starostin, S. Welzel, Y. Liu, B. van der VeldenSchuermans, J. B. Bouwstra, M. C. M. van de Sanden and H. W. de Vries, Eur. Phys. J.: Appl. Phys., 2015, 71, 20803.

34 A. S. Meshkova, Y. Liu, F. M. Elam, S. A. Starostin, M. C. M. van de Sanden and H. W. de Vries, Plasma Processes Polym., 2017, e1700093.

35 N. J. Harrick, J. Phys. Chem., 1960, 64, 1110-1114.

36 W. A. Pliskin and H. S. Lehman, J. Electrochem. Soc., 1965, 112, 1013-1019.

37 N. Rochat, A. Chabli, F. Bertin, M. Olivier, C. Vergnaud and P. Mur, J. Appl. Phys., 2002, 91, 5029-5034. 
38 G. Laroche, J. Fitremann and N. Gherardi, Appl. Surf. Sci., 2013, 273, 632-637.

39 W. Bensch and W. Bergholz, Semicond. Sci. Technol., 1990, 5, 421-428.

40 C. Martinet and R. A. B. Devine, J. Non-Cryst. Solids, 1995, 187, 96-100.

41 M. K. Gunde, Phys. B, 2000, 292, 286-295.

42 M. C. Payne and J. C. Inkson, J. Non-Cryst. Solids, 1984, 68, 351-360.

43 S. W. de Leeuw and M. F. Thorpe, Phys. Rev. Lett., 1985, 55, 2879-2882.

44 F. L. Galeener and G. Lucovsky, Phys. Rev. Lett., 1976, 37, 1474-1477.

45 A. Parikh and D. Allara, J. Chem. Phys., 1992, 96, 927-945.

46 R. M. Almeida, Phys. Rev. B: Condens. Matter Mater. Phys., 1992, 45, 161-170.

47 D. W. Berreman, Phys. Rev., 1963, 130, 2193-2198.

48 T. Hirata, J. Phys. Chem. Solids, 1997, 58, 1497-1501.

49 G. Lucovsky, C. K. Wong and W. B. Pollard, J. Non-Cryst. Solids, 1983, 59-60, 839-846.

50 P. G. Pai, S. S. Chao, Y. Takagi and G. Lucovsky, J. Vac. Sci. Technol., A, 1986, 4, 689-694.

51 C. T. Kirk, Phys. Rev. B: Condens. Matter Mater. Phys., 1988, 38, 1255-1273.
52 C. Vallee, A. Goullet, A. Granier, A. van der Lee, J. Durand and C. Marliere, J. Non-Cryst. Solids, 2000, 272, 163-173.

53 M. Creatore, J.-C. Cigal, G. M. W. Kroesen and M. C. M. van de Sanden, Thin Solid Films, 2005, 484, 104-112.

54 M. Creatore, S. M. Rieter, Y. Barrell, M. C. M. van de Sanden, R. Vernhes and L. Martinu, Thin Solid Films, 2008, 516, 85478553.

55 P. Lange, J. Appl. Phys., 1989, 66, 201-204.

56 J. S. Chou and S. C. Lee, J. Appl. Phys., 1995, 77, 1805-1807. 57 M. Nakamura, Y. Mochizuki, K. Usami, Y. Itoh and T. Nozaki, J. Electrochem. Soc., 1985, 132, 482-488.

58 E. Hensel, K. Wollschlager, D. Schulze, U. Kreissig, W. Skorupa and J. Finster, Surf. Interface Anal., 1985, 7, 207-210.

59 I. W. Boyd and J. I. B. Wilson, Appl. Phys. Lett., 1987, 50, 320322.

60 J. A. Theil, D. V Tsu, M. W. Watkins, S. S. Kim and G. Lucovsky, J. Vac. Sci. Technol., A, 1990, 8, 1374-1381.

61 T. M. Parrill, J. Mater. Res., 1994, 9, 723-730.

62 R. A. B. Devine, J. Vac. Sci. Technol., A, 1988, 6, 3154-3156.

63 J. Coates, in Encyclopedia of Analytical Chemistry, ed. R. A. Meyers, John Wiley \& Sons Ltd, Chichester, 2000, pp. 10815-10837.

64 L. B. Capeletti, I. M. Baibich, I. S. Butler and J. H. Z. dos Santos, Spectrochim. Acta, Part A, 2014, 133, 619-625. 